\title{
Study on the Seismic Effect of the Interbedded Soil Layer in the Yinchuan Alluvial Plain
}

\author{
Shun Yang $\mathbb{D}^{1}{ }^{1}$ Xin Han, ${ }^{2}$ Qiyun Lei, ${ }^{1}$ Sihan Yu, ${ }^{1}$ and Chao Liu ${ }^{1}$ \\ ${ }^{1}$ Earthquake Agency of Ningxia Hui Autonomous Region, Yinchuan 750001, China \\ ${ }^{2}$ Gansu Earthquake Agency, Lanzhou 730000, China \\ Correspondence should be addressed to Shun Yang; yangshunyantu@126.com
}

Received 1 June 2021; Revised 28 July 2021; Accepted 24 August 2021; Published 8 September 2021

Academic Editor: Xiaxin Tao

Copyright (c) 2021 Shun Yang et al. This is an open access article distributed under the Creative Commons Attribution License, which permits unrestricted use, distribution, and reproduction in any medium, provided the original work is properly cited.

This paper presents a numerical analysis of two types of representative site profiles in the Yinchuan Plain under earthquake loading. The analyzed soil profiles, based on borehole investigations performed over the years, are used to explore the seismic response of the sites in this area. In total, eleven stratified soil models are used in this study, which can be grouped into two categories: a single interbedded soil model and multiple interbedded soil model. A one-dimensional equivalent linearization method is applied to evaluate the seismic response of different soil models under four exceeding probabilities in terms of peak ground acceleration $(P G A)$, peak ground velocity $(P G V)$, peak ground displacement $(P G D)$, and spectral acceleration $(S a)$. The results show that the significant amplification effect of $P G A$ occurs in rare and extremely rare earthquakes, with an amplification ratio of 1.4 1.7 when the single silty clay layer is located at the model ground. In this scenario, the spectral acceleration is amplified at a period of approximately $1.0 \mathrm{~s}$. For the multilayered soil cases, the amplification effect tends to decrease, whereas the characteristic periods increase with increasing numbers of soil layers and the ground acceleration is deamplified under a high motion intensity when the number of soil layers is $\geq 5$. This study, to a certain degree, has reference value for seismic microzonation in this area.

\section{Introduction}

The Yinchuan alluvial plain is located in the middle part of the Yellow River Basin. The thickness of the Quaternary sediments in the plain can reach thousands of meters. The interbedded stratigraphic structure is widely developed within 100 meters in the near surface and is mainly interbedded with silty clay and fine sand. On the other hand, active faults have developed in this plain area, and strong earthquakes have occurred throughout history, such as the 1709 Pingluo $M 8$ earthquake. Recently, with the policy that supports Ningxia in building a pilot zone for ecological protection and high-quality development of the Yellow River Basin, large numbers of infrastructures, industrial parks, and other projects have been built on the Yinchuan Plain. One of the important steps is thus to evaluate the seismic risk of this area and to estimate the amplitude of ground motions to reduce earthquake-induced disasters.
Therefore, research on seismic effects on the interbedded soil layer in the Yinchuan alluvial plain can provide a reference value for engineering seismic design and disaster prevention in the Yinchuan Plain.

In 1928, Bo et al. [1] realized the importance of site conditions on the site seismic response when analyzing the seismic damage to buildings during the 1906 San Francisco earthquake. This finding has been shown by the following earthquakes: the 1923 Kanto earthquake in Japan, 1967 Venezuela earthquake, 1968 and 1970 Manila earthquakes in the Philippines, 1975 Haicheng earthquake in China, 1976 Tangshan earthquake, 1985 Mexico earthquake, and 2008 Wenchuan earthquake. In general, site conditions refer to local geological conditions, such as the overlying soil layer, landforms, and fracture zone near the surface of the site. With the development of strong earthquake observations and theoretical studies, numerous studies have shown that the seismic effect at the site is closely related to the soil 
properties, soil structures, overburden thickness, motion intensities, and other parameters. Essentially, the effect of site conditions on earthquake damage is the result of significant amplification or attenuation of the ground motion that comes from the bedrock. In recent years, the effect of near-surface soil conditions on ground motions has received increasing attention, and strong-motion observations demonstrate that the amplification effect of the surface ground motion is more evident in soft to medium-hard clay and sandy soil grounds than in hard soil conditions. In addition, the amplification effect has a large range of periods for soft to medium-hard grounds, generally in the range of $0.3 \sim 1.1 \mathrm{~s}$ [1]. In contrast, the surface spectral acceleration for the hard soil site shows a significant amplification in the higher frequency range. Using a one-dimensional equivalent linearization method, Bo et al. [2] investigated the influence of local site conditions on the peak values and the spectral characteristics of ground motion. Bo et al. [2] summarized some recent advances in seismic site effects and further analyzed the influence of different soil structures on the characteristic period of the surface acceleration response spectrum based on several typical site profiles. Chen and Chen [3] conducted a numerical analysis on the influence of the burial depth and thickness of a soft soil layer on the ground motion at a deep site. The analysis showed that, with a special sediment thickness or input ground motion, the amplification effect decreases as the softness of the surface soil layer increases, and the variations in the peak ground accelerations and amplification ratios are not evident when a limit thickness is reached. Interestingly, the deamplification effect of ground motions can be observed when a very thick soft soil layer is located at the ground, acting as a natural damper. Zhou et al. [4] demonstrated that the thickness of a hard interlayer also has an obvious influence on the peak ground acceleration and spectral acceleration, and the presence of a hard interlayer can reduce the soil nonlinearity. Although some research on seismic site effects has been carried out from various aspects (e.g., [5-20]), few reports on the effect of interbedded stratigraphic structure on seismic responses at sites in alluvial plains are available.

\section{Soil Model}

Soil is a strongly nonlinear material, and the greater the ground motion is, the stronger the nonlinearity. The equivalent linearization method is one of the main methods to estimate the nonlinear characteristics of a site under seismic action. The basic idea is to treat the soil as a viscoelastic material; the overall dynamics have approximately the same effect, with an equivalent shear modulus and equivalent damping ratio under different strain amplitudes; the shear moduli and damping ratios are replaced, and the nonlinear problem becomes a linear problem, usually by analyzing the fluctuation in the frequency domain or when time domain iterations are complete. In essence, the equivalent linearization method is still a linear method that simulates the nonlinear constitutive history of soil with only the "equivalent linear" mechanism. However, the equivalent linearization method is still the mainstream current dynamic analysis. This method has many experimental results, its form is relatively intuitive and simple, and it has accumulated much engineering experience [21]. Considering the above reasons and its consistency with existing codes and engineering applications, this method is still used to calculate the seismic response of the soil layer in this paper. This method is physically meaningful and requires fewer soil parameters. It requires only the soil density, shear wave velocity, and the curves of shear stiffness degradation and damping build-up with increasing shear strains. These parameters are determined through laboratory tests and field investigation, as listed in Tables 1 and 2.

In the study area, a number of borehole investigations have been performed for different purposes; thus, the soil profiles are collected from the literature and reports. Based on the available soil profiles, it is possible to group these profiles into two categories: a single interbedded soil model and multiple interbedded soil model. Considering different positions and numbers of silty clay layers, eleven stratified soil models are used in this study, as shown in Figure 1.

\section{Input Seismic Load}

Because of the shortage of strong earthquake data in this area, the synthesis method is used in this calculation. This project adopts the probabilistic seismic hazard analysis method stipulated in the national standard "Evaluation of Seismic Safety for Engineering Sites" (GB 17741-2005). The specific steps are as follows:

(1) On the basis of regional and near-field regional seismicity, regional and near-field regional seismotectonic backgrounds, and the seismic zones and the estimation of the seismic trend of each seismic zone over the next hundred years, the potential source areas of each seismic zone are delineated.

(2) The seismicity parameters of the seismic zone and potential source area are determined.

(3) The seismic hazard analysis for each site is carried out one by one using the selected attenuation relation of ground motion and the probability analysis method of seismic hazards.

(4) The acceleration response spectra on bedrock with different risk levels are evaluated for each of the sites.

On the basis of each acceleration response spectra on bedrock, the corresponding ground motion input is synthesized according to the method stipulated in the "Evaluation of Seismic Safety for Engineering Sites" (GB 177412005). The specific steps are as follows:

(1) The target response spectrum is converted to the corresponding power spectrum by

$$
S(\omega)=\frac{\varepsilon / \pi \omega S_{a}^{2}(\omega)}{\{-\operatorname{Ln}[-\pi / \omega T \operatorname{Ln}(1-r)]\}},
$$


TABle 1: Models and soil mechanical parameters.

\begin{tabular}{|c|c|c|c|c|c|c|}
\hline Model & Soil name & Layer depth (m) & Soil thickness (m) & $\mathrm{Vs} / \mathrm{m} \cdot \mathrm{s}^{-1}$ & $\rho / \mathrm{t} \cdot \mathrm{m}^{-3}$ & Soil type number \\
\hline \multirow{5}{*}{ Model 1-1 } & Silty clay & 10 & 10 & 265 & 1.95 & 1 \\
\hline & Fine sand & 20 & 10 & 293 & 1.92 & 6 \\
\hline & Fine sand & 30 & 10 & 359 & 1.92 & 6 \\
\hline & Fine sand & 40 & 10 & 426 & 1.92 & 6 \\
\hline & Fine sand & 50 & 10 & 500 & 1.92 & 6 \\
\hline \multirow{5}{*}{ Model 1-2 } & Fine sand & 10 & 10 & 226 & 1.90 & 6 \\
\hline & Silty clay & 20 & 10 & 337 & 1.97 & 2 \\
\hline & Fine sand & 30 & 10 & 369 & 1.92 & 6 \\
\hline & Fine sand & 40 & 10 & 433 & 1.92 & 6 \\
\hline & Fine sand & 50 & 10 & 500 & 1.92 & 6 \\
\hline \multirow{5}{*}{ Model 1-3 } & Fine sand & 10 & 10 & 276 & 1.90 & 6 \\
\hline & Fine sand & 20 & 10 & 287 & 1.91 & 6 \\
\hline & Silty clay & 30 & 10 & 372 & 2.00 & 3 \\
\hline & Fine sand & 40 & 10 & 433 & 1.92 & 6 \\
\hline & Fine sand & 50 & 10 & 500 & 1.92 & 6 \\
\hline \multirow{5}{*}{ Model 1-4 } & Fine sand & 10 & 10 & 236 & 1.90 & 6 \\
\hline & Fine sand & 20 & 10 & 311 & 1.87 & 6 \\
\hline & Fine sand & 30 & 10 & 388 & 1.92 & 6 \\
\hline & Silty clay & 40 & 10 & 441 & 2.05 & 4 \\
\hline & Fine sand & 50 & 10 & 500 & 1.92 & 6 \\
\hline \multirow{5}{*}{ Model 1-5 } & Fine sand & 10 & 10 & 222 & 1.90 & 6 \\
\hline & Fine sand & 20 & 10 & 307 & 1.91 & 6 \\
\hline & Fine sand & 30 & 10 & 389 & 1.92 & 6 \\
\hline & Fine sand & 40 & 10 & 453 & 1.96 & 6 \\
\hline & Silty clay & 50 & 10 & 500 & 2.1 & 5 \\
\hline \multirow{7}{*}{ Model 2-1 } & Fine sand & 7 & 7 & 207 & 1.89 & 6 \\
\hline & Fine sand & 14 & 7 & 271 & 1.90 & 6 \\
\hline & Fine sand & 21 & 7 & 329 & 1.91 & 6 \\
\hline & Fine sand & 28 & 7 & 373 & 1.92 & 6 \\
\hline & Fine sand & 35 & 7 & 419 & 1.93 & 6 \\
\hline & Fine sand & 42 & 7 & 463 & 1.94 & 6 \\
\hline & Silty clay & 50 & 8 & 500 & 2.1 & 5 \\
\hline \multirow{7}{*}{ Model 2-2 } & Fine sand & 7 & 7 & 200 & 1.89 & 6 \\
\hline & Fine sand & 14 & 7 & 281 & 1.90 & 6 \\
\hline & Fine sand & 21 & 7 & 323 & 1.91 & 6 \\
\hline & Silty clay & 28 & 8 & 399 & 1.96 & 3 \\
\hline & Fine sand & 35 & 7 & 408 & 1.93 & 6 \\
\hline & Fine sand & 42 & 7 & 443 & 1.94 & 6 \\
\hline & Fine sand & 50 & 7 & 500 & 1.96 & 6 \\
\hline \multirow{7}{*}{ Model 2-3 } & Fine sand & 7 & 7 & 218 & 1.89 & 6 \\
\hline & Fine sand & 14 & 7 & 279 & 1.90 & 6 \\
\hline & Fine sand & 21 & 7 & 319 & 1.91 & 6 \\
\hline & Silty clay & 28 & 7 & 388 & 1.96 & 3 \\
\hline & Fine sand & 35 & 7 & 412 & 1.93 & 6 \\
\hline & Fine sand & 42 & 7 & 451 & 1.94 & 6 \\
\hline & Silty clay & 50 & 8 & 500 & 2.1 & 5 \\
\hline \multirow{7}{*}{ Model 2-4 } & Silty clay & 7 & 7 & 269 & 1.92 & 1 \\
\hline & Fine sand & 14 & 7 & 279 & 1.90 & 6 \\
\hline & Fine sand & 21 & 7 & 322 & 1.91 & 6 \\
\hline & Silty clay & 28 & 7 & 393 & 1.96 & 3 \\
\hline & Fine sand & 35 & 7 & 410 & 1.93 & 6 \\
\hline & Fine sand & 42 & 7 & 448 & 1.94 & 6 \\
\hline & Silty clay & 50 & 8 & 500 & 2.1 & 5 \\
\hline
\end{tabular}


TABle 1: Continued.

\begin{tabular}{|c|c|c|c|c|c|c|}
\hline Model & Soil name & Layer depth $(\mathrm{m})$ & Soil thickness (m) & $\mathrm{Vs} / \mathrm{m} \cdot \mathrm{s}^{-1}$ & $\rho / \mathrm{t} \cdot \mathrm{m}^{-3}$ & Soil type number \\
\hline \multirow{7}{*}{ Model 2-5 } & Silty clay & 7 & 7 & 269 & 1.92 & 1 \\
\hline & Fine sand & 14 & 7 & 272 & 1.90 & 6 \\
\hline & Silty clay & 21 & 7 & 372 & 1.96 & 3 \\
\hline & Fine sand & 28 & 7 & 390 & 1.96 & 3 \\
\hline & Silty clay & 35 & 7 & 431 & 2.0 & 4 \\
\hline & Fine sand & 42 & 7 & 448 & 1.94 & 6 \\
\hline & Fine sand & 50 & 8 & 500 & 1.96 & 6 \\
\hline \multirow{7}{*}{ Model 2-6 } & Silty clay & 7 & 7 & 269 & 1.92 & 1 \\
\hline & Fine sand & 14 & 7 & 272 & 1.90 & 6 \\
\hline & Silty clay & 21 & 7 & 372 & 1.96 & 3 \\
\hline & Fine sand & 28 & 7 & 390 & 1.96 & 3 \\
\hline & Silty clay & 35 & 7 & 431 & 2.0 & 4 \\
\hline & Fine sand & 42 & 7 & 448 & 1.94 & 6 \\
\hline & Silty clay & 50 & 8 & 500 & 2.10 & 5 \\
\hline
\end{tabular}

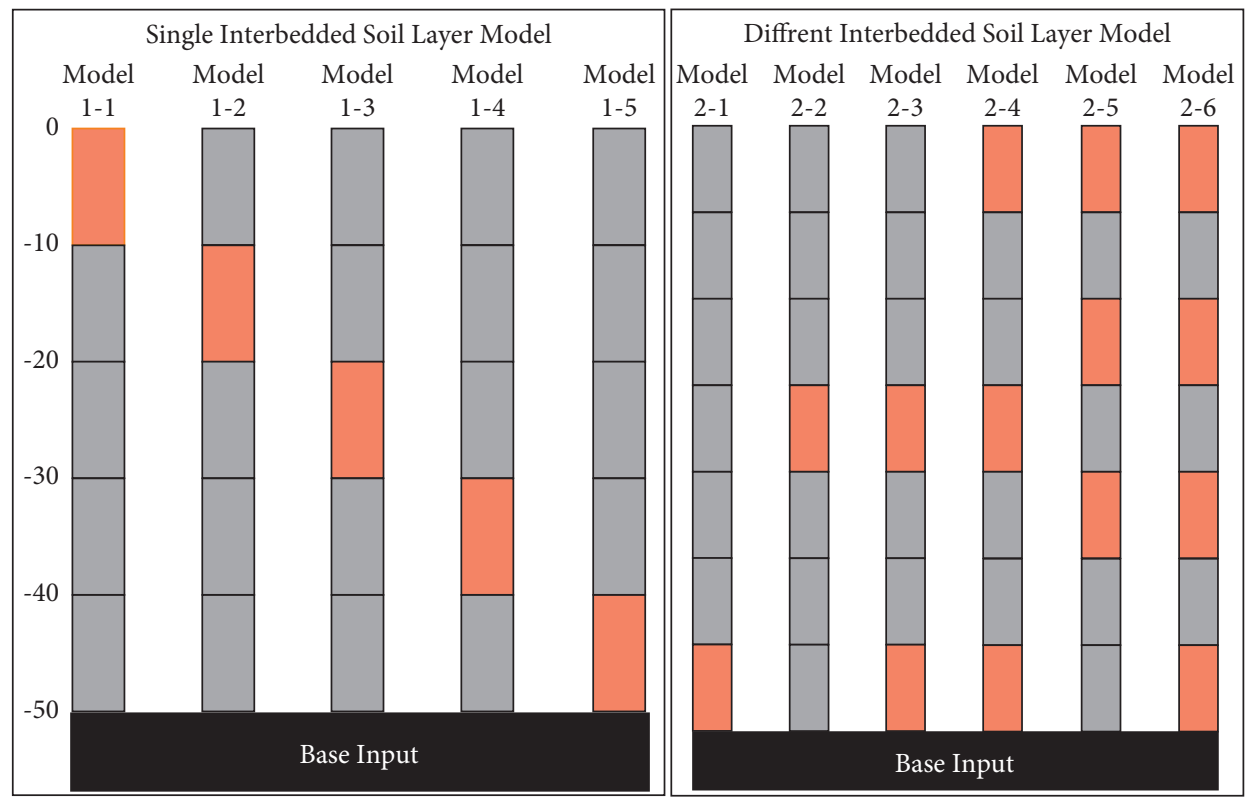

Silty Clay

Fine Sand

Figure 1: Schematic diagram of soil models.

Table 2: Dynamic nonlinear parameters for different soil types.

\begin{tabular}{lcccccccccc}
\hline \multirow{2}{*}{ Soil type number } & \multirow{2}{*}{ Soil name } & \multirow{2}{*}{ Parameter } & \multicolumn{5}{c}{$\gamma_{d}\left(10^{-4}\right)$} \\
& & & 0.05 & 0.1 & 0.5 & 1 & 5 & 10 & 50 & 100 \\
\hline \multirow{2}{*}{1} & \multirow{2}{*}{ Silty clay } & $G_{d} / G_{d \max }$ & 0.9797 & 0.9603 & 0.8285 & 0.7073 & 0.3258 & 0.1946 & 0.0461 & 0.0236 \\
& & $\lambda$ & 0.0054 & 0.0095 & 0.0325 & 0.0510 & 0.1032 & 0.1199 & 0.1383 & 0.1411 \\
\hline \multirow{2}{*}{2} & \multirow{2}{*}{ Silty clay } & $G_{d} / G_{d \max }$ & 0.9903 & 0.9809 & 0.9112 & 0.8369 & 0.5065 & 0.3391 & 0.0931 & 0.0488 \\
& & $\lambda$ & 0.0060 & 0.0085 & 0.0188 & 0.0258 & 0.0459 & 0.0535 & 0.0630 & 0.0646 \\
\hline \multirow{2}{*}{3} & \multirow{2}{*}{ Silty clay } & $G_{d} / G_{d \max }$ & 0.9866 & 0.9736 & 0.8806 & 0.7867 & 0.4245 & 0.2694 & 0.0687 & 0.0356 \\
& & $\lambda$ & 0.0071 & 0.0111 & 0.0296 & 0.0431 & 0.0822 & 0.0960 & 0.1124 & 0.1150 \\
\hline \multirow{2}{*}{4} & \multirow{2}{*}{ Silty clay } & $G_{d} / G_{d \max }$ & 0.9845 & 0.9696 & 0.8643 & 0.7610 & 0.3891 & 0.2415 & 0.0599 & 0.0309 \\
& & $\lambda$ & 0.0075 & 0.0112 & 0.0267 & 0.0371 & 0.0640 & 0.0726 & 0.0823 & 0.0837 \\
\hline \multirow{2}{*}{5} & \multirow{2}{*}{ Silty clay } & $G_{d} / G_{d \max }$ & 0.9836 & 0.9678 & 0.8572 & 0.7501 & 0.3752 & 0.2309 & 0.0566 & 0.0291 \\
& & $\lambda$ & 0.0119 & 0.0176 & 0.0420 & 0.0582 & 0.0994 & 0.1122 & 0.1264 & 0.1285 \\
\hline
\end{tabular}


TABLE 2: Continued.

\begin{tabular}{lccccccccccc}
\hline \multirow{2}{*}{ Soil type number } & \multirow{2}{*}{ Soil name } & \multirow{2}{*}{ Parameter } & \multicolumn{9}{c}{$\gamma_{d}\left(10^{-4}\right)$} \\
& & & 0.05 & 0.1 & 0.5 & 1 & 5 & 10 & 50 \\
\hline \multirow{2}{*}{6} & \multirow{2}{*}{ Fine sand } & $G_{d} / G_{d \max }$ & 0.9903 & 0.9809 & 0.9112 & 0.8369 & 0.5064 & 0.3391 & 0.0931 & 0.0488 \\
& & $\lambda$ & 0.0086 & 0.0118 & 0.0245 & 0.0327 & 0.0552 & 0.0634 & 0.0736 & 0.0753 \\
\hline \multirow{2}{*}{7} & \multirow{2}{*}{ Bed rock } & $G_{d} / G_{d \max }$ & 1.000 & 1.000 & 1.000 & 1.000 & 1.000 & 1.000 & 1.000 & 1.000 \\
& & $\lambda$ & 0.5 & 0.5 & 0.5 & 0.5 & 0.5 & 0.5 & 0.5 & 0.5 \\
\hline
\end{tabular}

where $S(\omega)$ is the power spectrum; $\varepsilon$ is the damping ratio; $S_{a}^{2}(\omega)$ is the target response spectrum; $T$ is duration; and $r$ is the exceeding probability of the target reaction spectrum.

(2) Stable Gaussian processes with zero mean values are generated by the trigonometric series superposition method:

$$
X(t)=\sum_{i=0}^{n} A_{i} \cos \left(\omega_{i} t+\varphi_{i}\right),
$$

where $A_{i}=\left[4 S\left(\omega_{i}\right) \Delta \omega\right]^{0.5}$ and the initial phase $\varphi_{i}$ is a uniformly distributed random variable during $[0-2 \pi]$.

(3) The stationary time history is multiplied by the nonstationary strength envelope to obtain the nonstationary acceleration time history:

$$
a(t)=\Psi(t) \cdot X(t) .
$$
form:

The nonstationary envelope function is of the following

$$
\Psi(t)=\left\{\begin{array}{ll}
\left(\frac{t}{t_{1}}\right)^{2} & 0<t \leq t_{1} \\
1 & t_{1}<t \leq t_{2} \\
e^{\left(-c\left(t-t_{2}\right)\right)} & t_{2}<t \leq T
\end{array},\right.
$$

where $t_{1}$ is the rising part of the peak, $t_{1}-t_{2}$ is the stationary segment of the peak, $T$ is the duration, and $c$ is the attenuation coefficient of the peak.

Eighty-five control points of the target response spectrum were selected within 0.04 6 seconds to ensure the precision of the target response spectrum fitting during the synthetic ground motion. In the process of synthesis, the time history of the synthesized acceleration accurately meets the peak acceleration of the target and approximates the response spectrum of the target acceleration by approximating the target spectrum step by step.

To maximize the reflection of the actual structure subjected to seismic action, site-specific ground motions are necessary. In this paper, artificial ground motions are generated by gradually approaching the target design spectrum in this area. Four ground motions with different amplitudes are generated based on the return period of this area, as shown in Figure 2. They correspond to exceeding probabilities of $63 \%$ (frequently occurring earthquakes),
$10 \%$ (normally occurring earthquakes), and 2\% (rarely occurring earthquakes) in 50 years and $1 \%$ in 100 years (extremely rarely occurring earthquakes).

\section{Results}

4.1. Model 1: Single Interbedded Soil Model. Five typical profiles with a single silty clay layer at different depths are built, as shown in Figure 1 (Model 1). The site profiles and corresponding soil parameters are input into the one-dimensional analysis model and then analyzed under different earthquake loadings. The results of peak ground acceleration (PGA), peak ground velocity (PGV), peak ground displacement (PGD), and spectral acceleration (Sa) are presented. As shown in Figure 3 and Table 3, silty clay with burial depths of 0-10 m (Model 1-1) and 41-50 m (Model 15) have a more evident amplification effect on the PGA response than the other models, with a maximum amplification ratio of approximately 1.7 . The amplification ratios increase with increasing motion intensity, and the maximum ratio is observed for the case of exceeding probabilities of $2 \%$ in 50 years. A further increase in motion intensity leads to a decrease in the amplification ratio due to the increase in the burial depth of silty clay. In addition, it is possible to see that the location of the silty clay layer significantly affects the calculated PGA response for strong ground motion. Under the action of normally occurring earthquakes, the amplification ratios range from 1.29 to 1.32 , showing a minor effect on the acceleration response. With regard to the PGV and PGD responses, amplification effects are also observed. However, these two parameters are less sensitive to the burial depth of the silty clay due to the small difference in amplification ratios. The fundamental site frequencies of Model 1-1 and Model 1-5 are close to a certain period of seismic waves of rarely occurring earthquakes (extremely rarely occurring earthquakes), so resonance is generated, resulting in the intensification of ground vibration and a significant amplification effect.

Figure 4 compares the spectral acceleration in the five cases. Under the action of frequently occurring earthquakes and normally occurring earthquakes, the burial depth of silty clay has little influence on the spectrum amplitudes and shapes, leading to similar spectrum curves. With the increase in motion intensities, a significant divergence in the spectral accelerations occurs in the short period range. Under rarely occurring earthquakes, the maximum spectral acceleration appears at a period of $0.4 \mathrm{~s}$ for Model 1-1, while the response spectrum reaches its peak value at a period of $0.2 \mathrm{~s}$ for other burial depths. This means that the ground soft soil layer amplifies the acceleration over a longer range of periods, and 

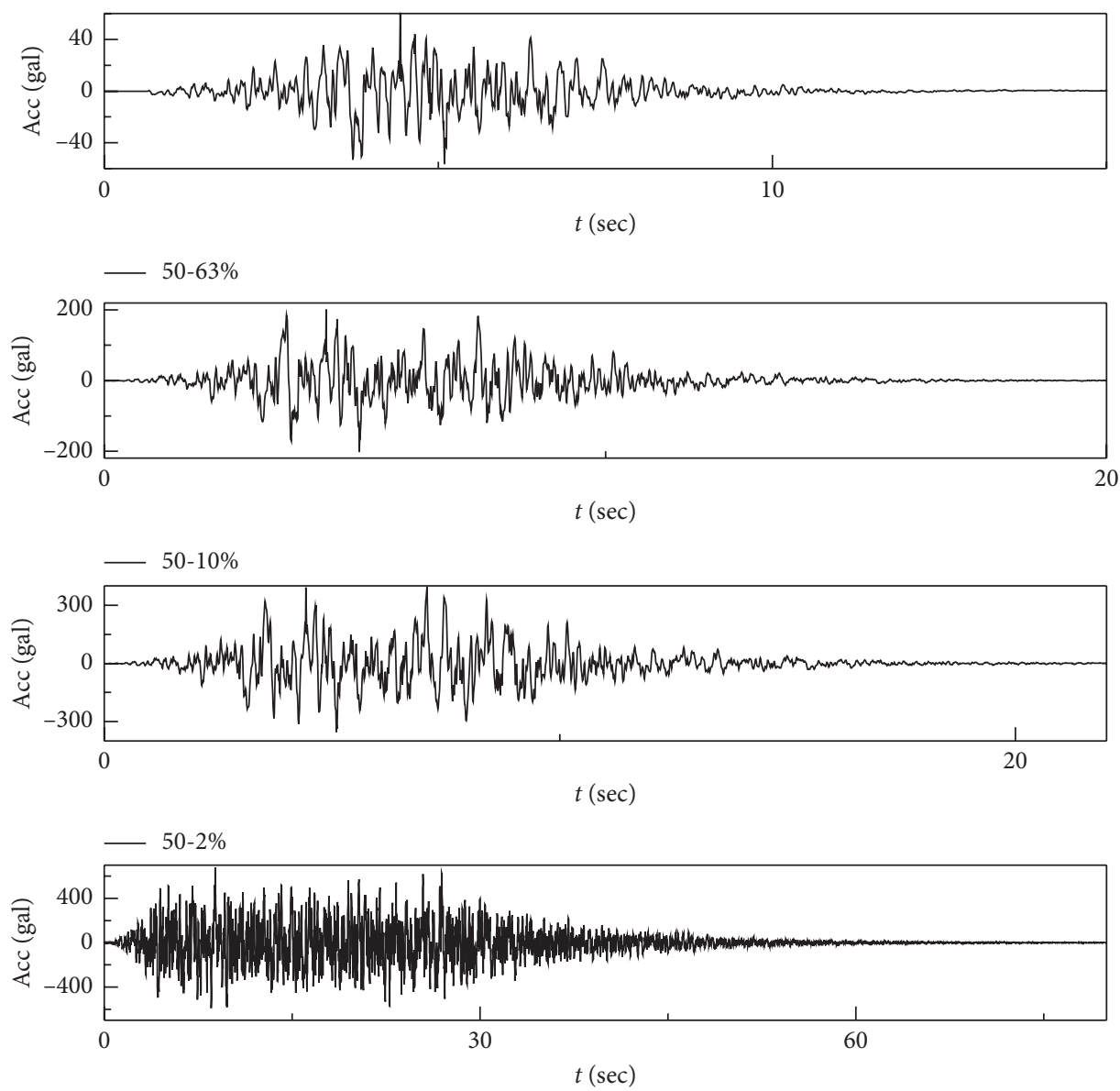

- $100-1 \%$

FIgURE 2: Ground motions under different probabilities.

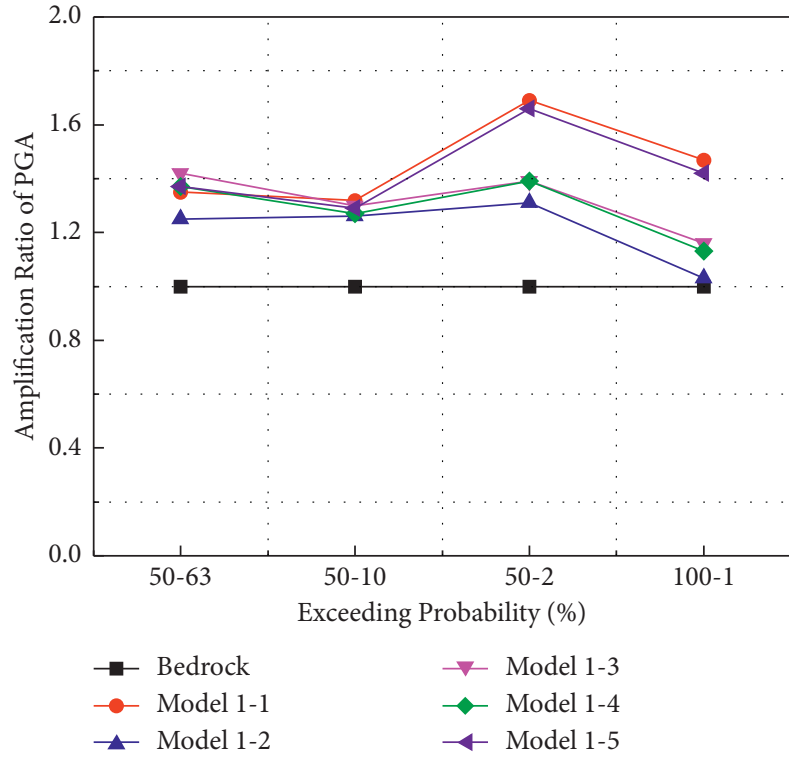

(a)

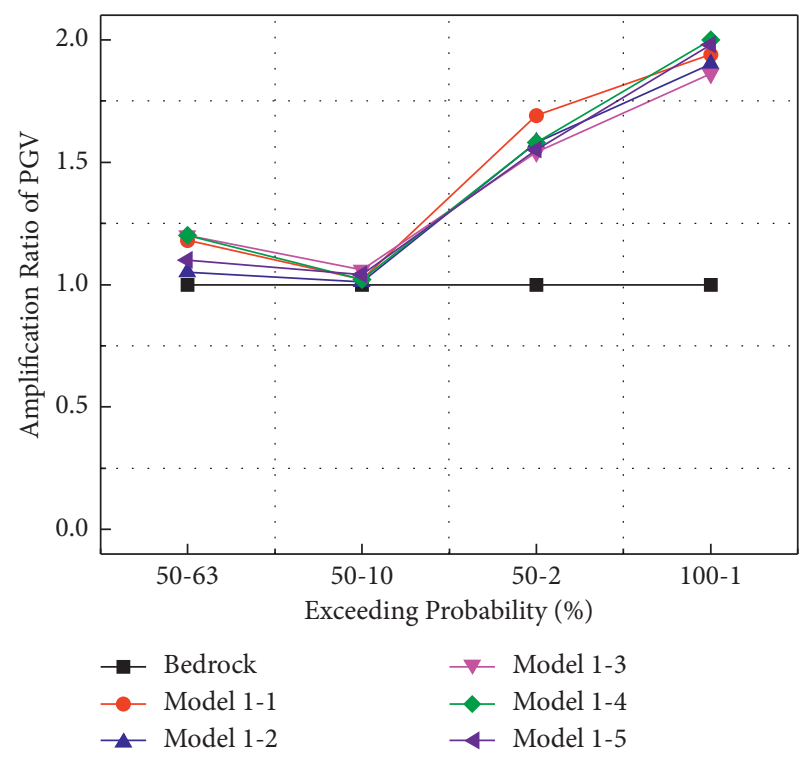

(b)

FIgUre 3: Continued. 


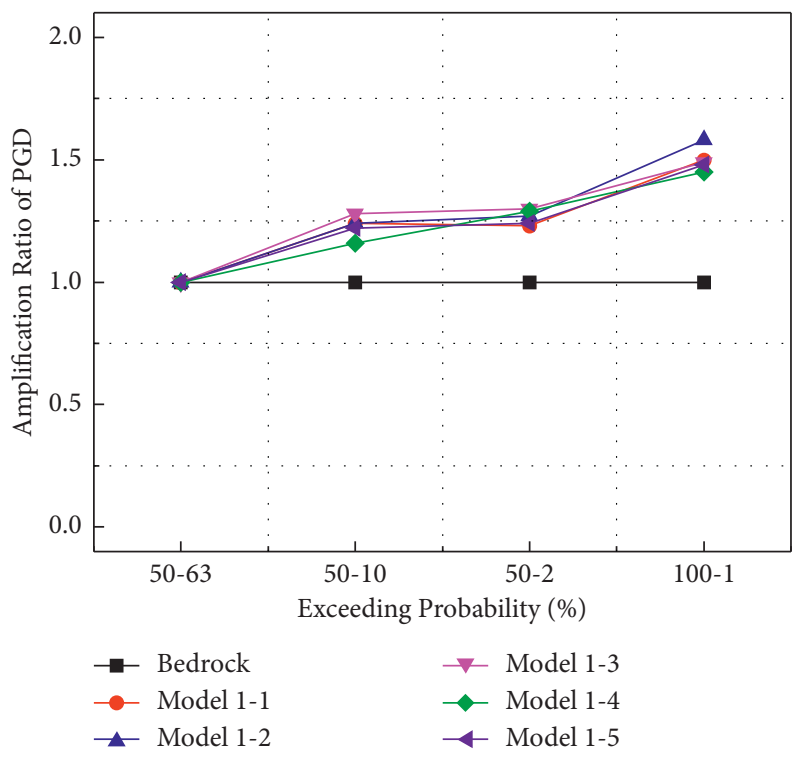

(c)

FIGURE 3: Amplification ratios of ground motion for the five single interbedded models under four seismic inputs.

TABLE 3: Ground motion amplification ratios for the five single interbedded models under four seismic inputs.

\begin{tabular}{lcccccc}
\hline & Bedrock input & Model 1-1 & Model 1-2 & Model 1-3 & Model 1-4 & Model 1-5 \\
\hline \multirow{3}{*}{ PGA (gal) } & $1(60)$ & $1.35(81.00)$ & $1.25(75.00)$ & $1.42(85.20)$ & $1.37(82.40)$ & $1.37(82.40)$ \\
& $1(202)$ & $1.32(266.6)$ & $1.26(254.6)$ & $1.30(262.4)$ & $1.27(256.8)$ & $1.29(261.3)$ \\
& $1(395)$ & $1.69(699.4)$ & $1.31(516.8)$ & $1.39(547.4)$ & $1.39(548.4)$ & $1.66(654.0)$ \\
& $1(680)$ & $1.47(998.0)$ & $1.03(698.2)$ & $1.16(786.0)$ & $1.13(770.4)$ & $1.42(963.8)$ \\
\hline \multirow{3}{*}{ PGV (cm/s) } & $1(4)$ & $1.18(4.70)$ & $1.05(4.20)$ & $1.20(4.80)$ & $1.20(4.80)$ & $1.10(4.40)$ \\
& $1(19)$ & $1.02(19.4)$ & $1.01(19.2)$ & $1.06(20.2)$ & $1.02(19.4)$ & $1.04(19.7)$ \\
& $1(35)$ & $1.69(59.2)$ & $1.58(55.4)$ & $1.54(53.8)$ & $1.58(55.2)$ & $1.55(54.1)$ \\
& $1(65)$ & $1.94(126.0)$ & $1.90(123.4)$ & $1.86(121.0)$ & $2.00(130.1)$ & $1.98(128.7)$ \\
\hline \multirow{3}{*}{ PGD (cm) } & $1(2)$ & $1.00(2.0)$ & $1.00(2.0)$ & $1.00(2.0)$ & $1.00(2.0)$ & $1.00(2.0)$ \\
& $1(5)$ & $1.24(6.2)$ & $1.24(6.2)$ & $1.28(6.4)$ & $1.16(5.8)$ & $1.22(6.1)$ \\
& $1(14)$ & $1.23(17.2)$ & $1.27(17.8)$ & $1.30(18.2)$ & $1.29(18.1)$ & $1.24(17.3)$ \\
\hline
\end{tabular}

Note. The values in the parentheses show the amplitudes of the PGA, PGV, and PGD.

such an influence is increased for extremely rarely occurring earthquakes. Under this earthquake type, the maximum value for the ground clay appears at a period of approximately $1.0 \mathrm{~s}$, and "twin peaks" occur. This is caused by the resonance of the soft surface layer. In general, the amplitude of the first peak (approximately $0.3 \mathrm{~s}$ ) increases as the burial depth of the silty clay layer increases. It can be speculated that the bottom clay layer suppresses the wave propagation at high frequencies, but the high-frequency component is amplified to some extent as it propagates from the bottom clay layer to the ground surface.

\subsection{Model 2: Multiple Interbedded Soil Models.} Considering different depths of the silty clay layer and relative locations with respect to the sand layer, six typical profiles are built, as shown in Figure 1 (Model 2). The results of the peak ground acceleration (PGA), peak ground velocity
(PGV), peak ground displacement (PGD), and spectral acceleration $(\mathrm{Sa})$ are presented in Figures 5 and 6 and Table 4.

As shown in Figure 5, under the action of frequently occurring earthquakes and normally occurring earthquakes, the difference in PGA amplification ratios for different soil models is small. Table 4 shows that the amplification coefficients are generally between 1.25 and 1.35. With increasing motion intensity, the amplification ratios show an increased divergence for different soil models. More specifically, for the same seismic inputs, the amplification ratios generally decrease with an increasing number of soil layers, particularly for high motion intensities. For extremely rarely occurring earthquakes, when the number of soil layers is greater than 3, the PGA amplification ratio is less than 1.0, which demonstrates that a larger number of soft clay layers isolate the propagation of ground motions to some degree. Compared to the results of Model 1, the larger number of 


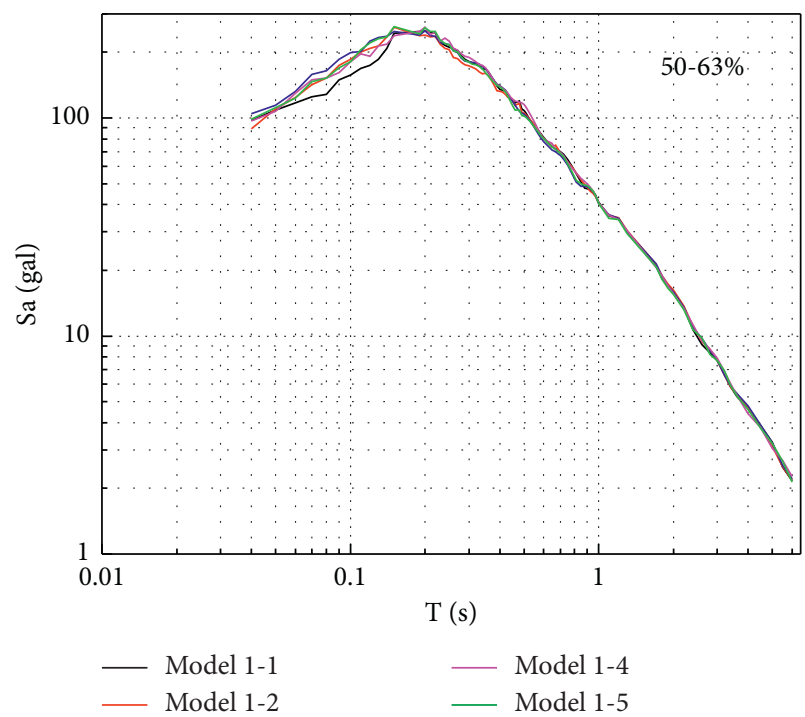

(a)

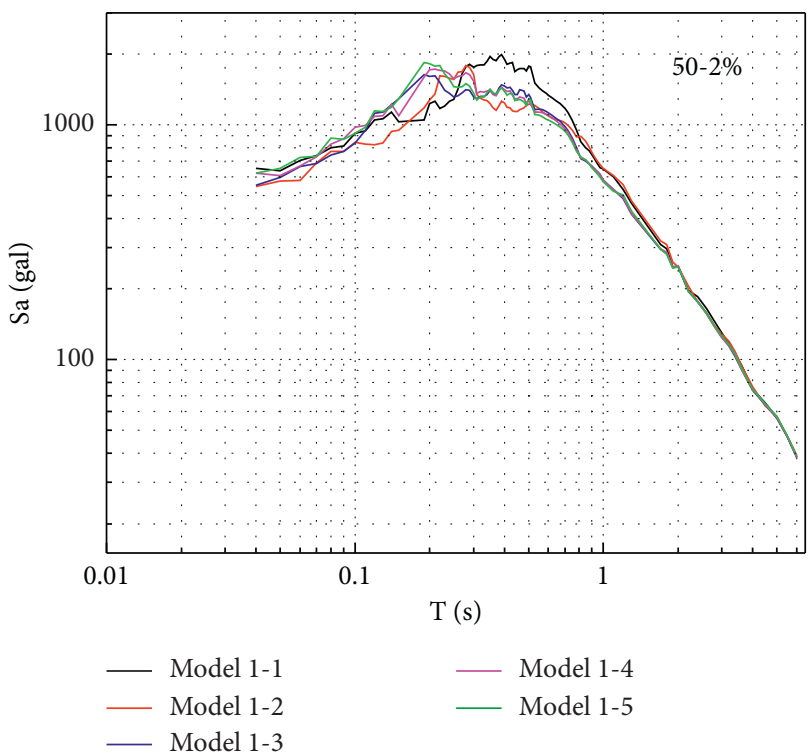

(c)

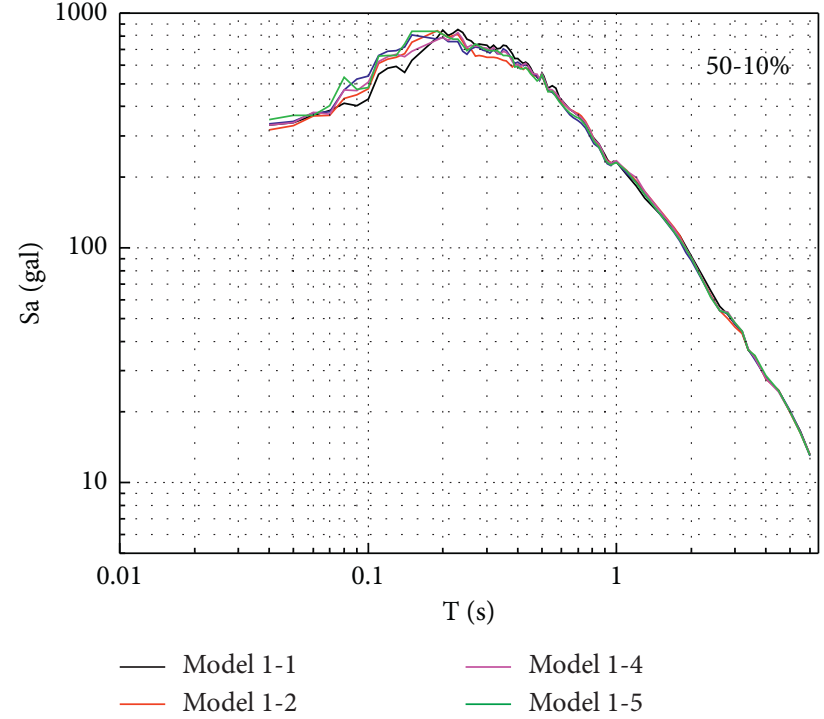

(b)

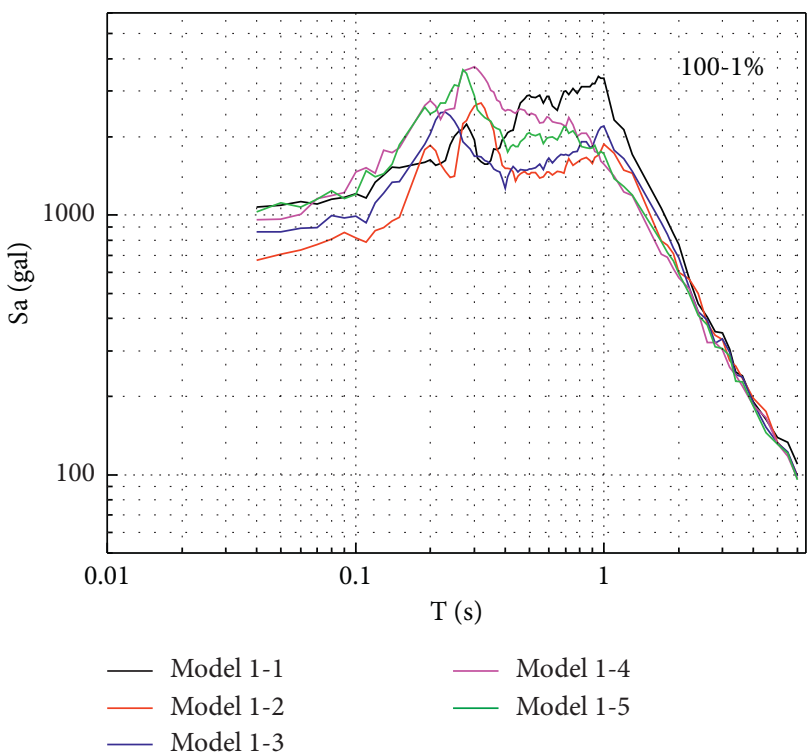

(d)

FIgURE 4: Spectral accelerations for the five single interbedded models under four seismic inputs.

soil layers increases the variation in the PGV and PGD responses but is still relatively small compared to the PGA response. Interestingly, the PGD response increases as the number of soil layers increases. This can be attributed to the large deformation in each clay layer because of the low stiffness.

The predominant period of ground motions is related to the thickness of the soil and the shear wave velocity of the soil. The increased number of interlayers will lead to stronger reflection and refraction of seismic waves. As a consequence, the high-frequency components are filtered out while the abundant long-period components are retained. As a result, the seismic waves differ greatly from the natural vibration period of the site, making the amplification ratio of the peak acceleration of the ground surface appear to be less than 1.0.

Figure 6 presents the corresponding spectral accelerations. Similarly, the difference in the spectral accelerations is minor for low motion intensity (i.e., frequently occurring earthquakes and normally occurring earthquakes), meaning that the soil structure has little influence. As motion 


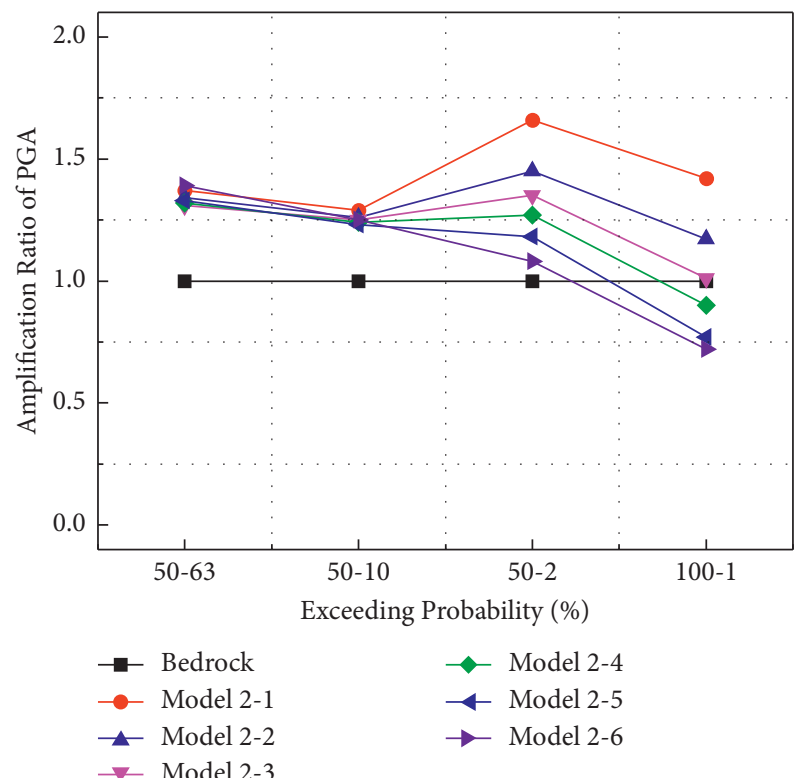

(a)

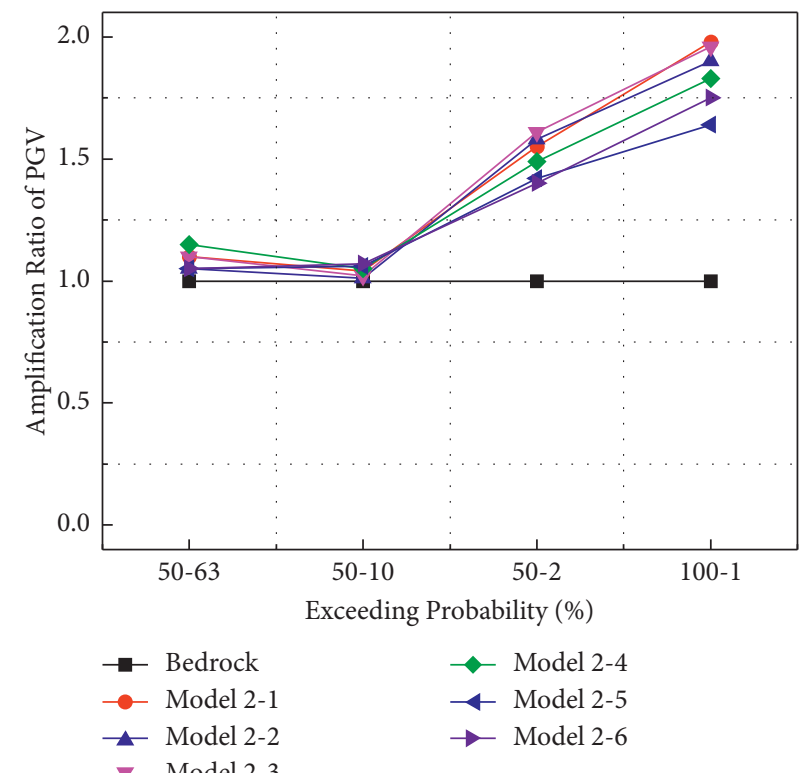

(b)

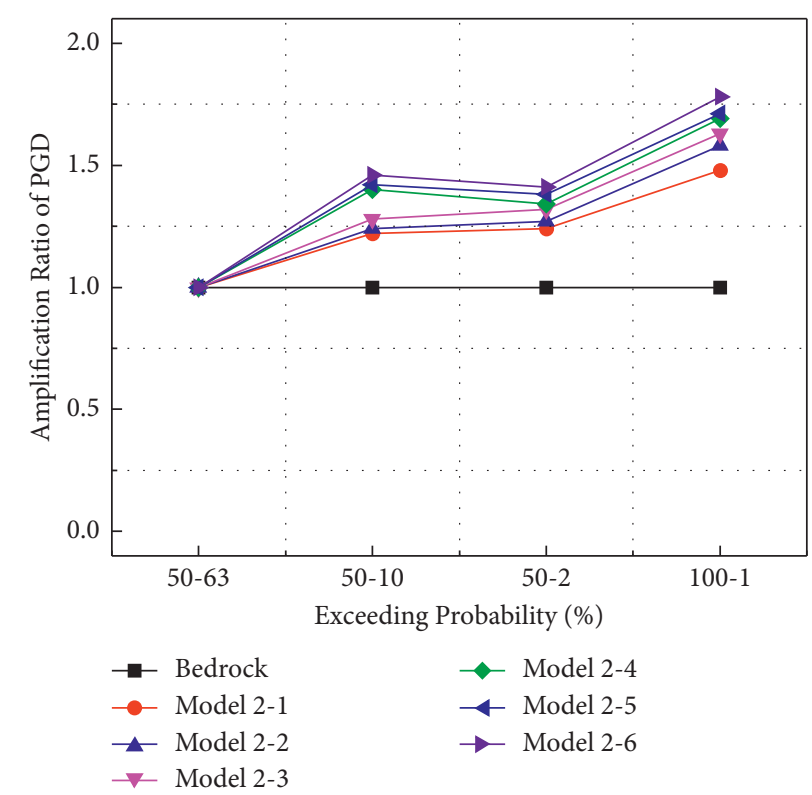

(c)

FIgURE 5: Amplification ratios of ground motion for the six multiple interbedded models under four seismic inputs.

intensities increase, a significant divergence in the spectral accelerations occurs in the low period range. The increased number of soil layers tends to decrease the acceleration response in the low period range, and the predominant period increases to a long period due to the significant stiffness degradation. This is more evident for extremely rarely occurring earthquakes. For instance, the amplitude of spectral acceleration decreases from 1300 gal in Model 2-1 to approximately 800 gal in Model 2-6 at a period of $0.3 \mathrm{~s}$, and the corresponding predominant period increases from $0.3 \mathrm{~s}$ to approximately $1.1 \mathrm{~s}$. This can be explained by the strong reflection and refraction of seismic waves in multilayered grounds, resulting in the filtering out of the high-frequency components of ground motion while amplifying the longperiod components. The results of Model 1 and Model 2 both highlight that the presence of a certain number of soil layers can effectively reduce the acceleration response spectrum at high frequencies. 

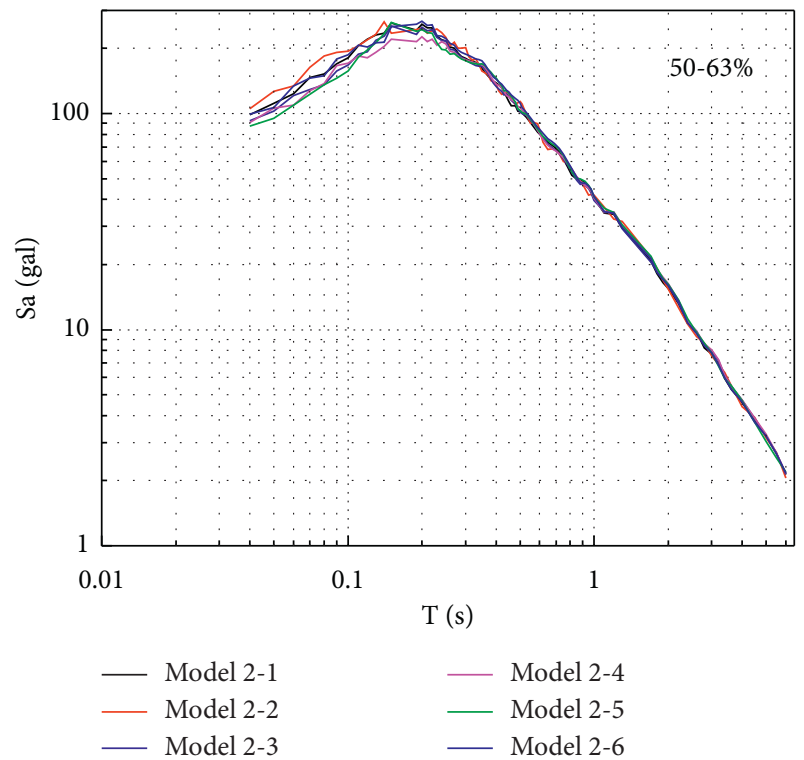

(a)

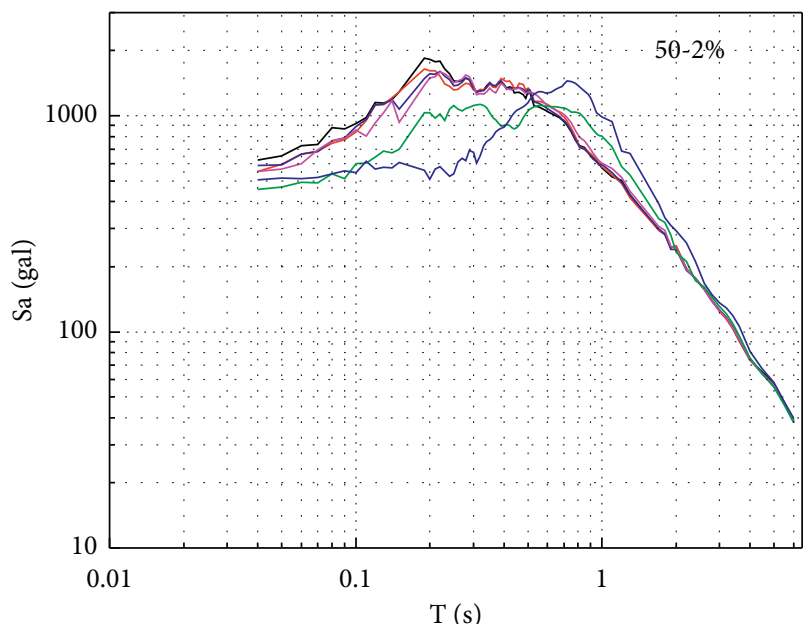

— Model 2-4

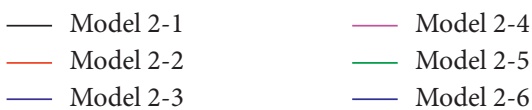

(c)
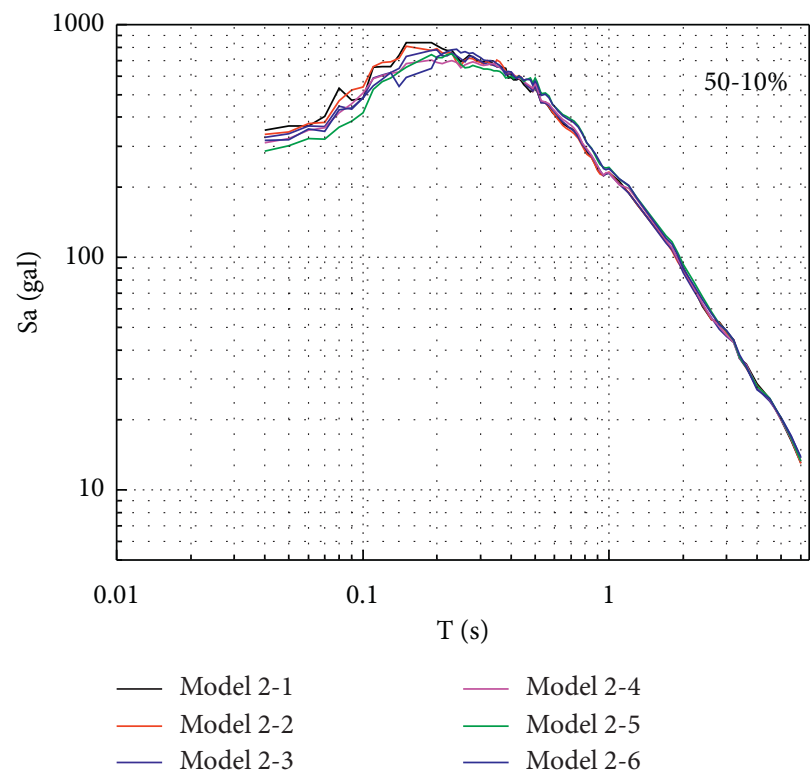

(b)
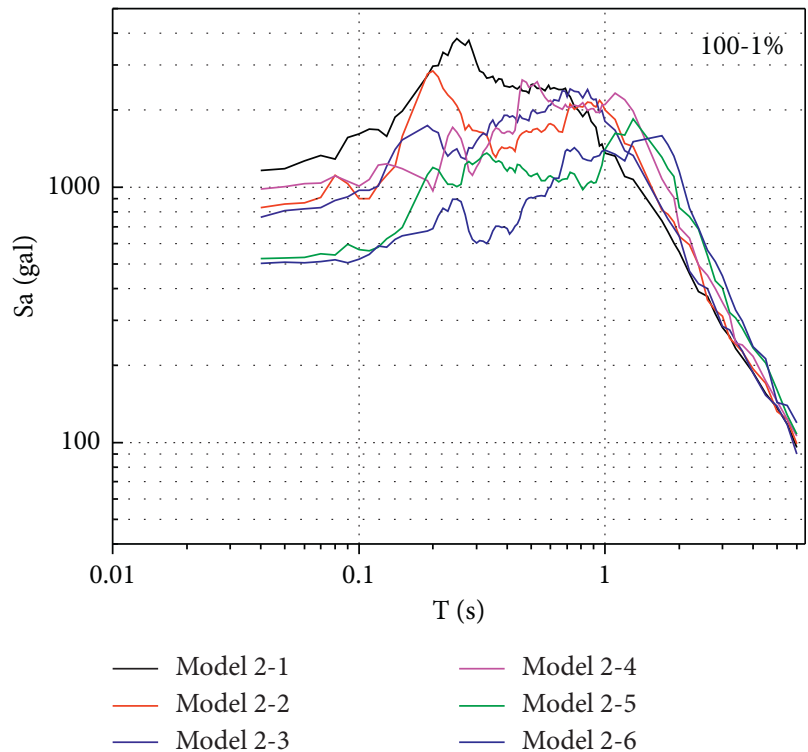

(d)

FIGURE 6: Spectral accelerations for the six multiple interbedded models under four seismic inputs.

TABLE 4: Ground motion amplification ratios for the six multiple interbedded models under four seismic inputs.

\begin{tabular}{cccccccc}
\hline & Bedrock input & Model 2-1 & Model 2-2 & Model 2-3 & Model 2-4 & Model 2-5 & Model 2-6 \\
\hline & $1(60)$ & $1.37(82.40)$ & $1.34(80.1)$ & $1.31(78.6)$ & $1.32(79.2)$ & $1.33(79.8)$ & $1.39(83.2)$ \\
PGA (gal) & $1(202)$ & $1.29(261.3)$ & $1.26(254.6)$ & $1.25(252.2)$ & $1.24(250.5)$ & $1.23(249.0)$ & $1.25(252.0)$ \\
& $1(395)$ & $1.66(654.0)$ & $1.45(573.5)$ & $1.35(534.2)$ & $1.27(501.7)$ & $1.18(467.6)$ & $1.08(427.4)$ \\
& $1(680)$ & $1.42(963.8)$ & $1.17(798.3)$ & $1.01(689.2)$ & $0.9(612.0)$ & $0.77(525.2)$ & $0.72(489.0)$ \\
\hline \multirow{3}{*}{ PGV (cm/s) } & $1(4)$ & $1.10(4.40)$ & $1.05(4.20)$ & $1.10(4.40)$ & $1.15(4.6)$ & $1.05(4.2)$ & $1.05(4.2)$ \\
& $1(19)$ & $1.04(19.7)$ & $1.01(19.2)$ & $1.02(19.4)$ & $1.05(20.0)$ & $1.06(20.2)$ & $1.07(20.3)$ \\
& $1(35)$ & $1.55(54.1)$ & $1.58(55.4)$ & $1.61(56.4)$ & $1.49(52.1)$ & $1.42(49.6)$ & $1.40(49.0)$ \\
& $1(65)$ & $1.98(128.7)$ & $1.9(123.4)$ & $1.96(127.4)$ & $1.83(119.2)$ & $1.64(106.3)$ & $1.75(113.8)$ \\
\hline & $1(2)$ & $1.00(2.0)$ & $1.00(2)$ & $1.00(2)$ & $1.00(2.0)$ & $1.00(2.0)$ & $1.00(2.0)$ \\
PGD (cm) & $1(5)$ & $1.22(6.1)$ & $1.24(6.2)$ & $1.28(6.4)$ & $1.4(7.0)$ & $1.42(7.10)$ & $1.46(7.30)$ \\
& $1(14)$ & $1.24(17.3)$ & $1.27(17.8)$ & $1.32(18.5)$ & $1.34(18.3)$ & $1.38(19.3)$ & $1.41(19.8)$ \\
& $1(24)$ & $1.48(35.6)$ & $1.58(36.0)$ & $1.63(39.2)$ & $1.69(37.1)$ & $1.71(41.0)$ & $1.78(42.8)$ \\
\hline
\end{tabular}




\section{Conclusions}

This paper analyzes the seismic response of different soil models that include different numbers and locations of silty clay layers. Based on the parametric analysis performed herein, the following conclusions can be drawn:

(1) When the silty clay is at the soil ground and bottom, significant amplification effects of the PGA for high motion intensity appear. Additionally, the predominant period is increased due to the presence of the ground clay layer. Important engineering facilities should avoid sites with silty clay at the top of the soil layer or treat the silty clay layer.

(2) As the numbers of soil layers and motion intensities increase, the amplification coefficient of the PGA gradually decreases to less than 1.0 for extremely rarely occurring earthquakes. The deamplification effect is observed for soil layer numbers greater than 3 in this study, thereby acting as a natural damper. However, the PGD shows the opposite trend due to the large deformation caused by the soft clay layers.

(3) The spectral accelerations are less affected by the presence of the soil layer for weak motion intensities. As motion intensities and the number of soil layers increase, the amplitude at high frequencies is generally deamplified, and the predominant period of the response spectrum becomes larger. In other words, in the case of large earthquakes, the greater the number of interlayered soil layers, the more obvious the amplification effect of the long-period ground motion.

\section{Data Availability}

The basic data used in this paper are from the measured data in each safety evaluation report.

\section{Conflicts of Interest}

The authors declare that they have no conflicts of interest.

\section{Acknowledgments}

This study was supported by the National Key Research and Development Program of China, No. 2017YFC1500101; Science and Technology Development Fund of Gansu Earthquake Agency, No. 2021M3; and Science and Technology Innovation Team of Ningxia Seismological Administration, No. CX2019-1.

\section{References}

[1] J. S. Bo, X. L. Li, and S. Y. Li, "Some progress of study on the effect of site conditions on ground motion," World Information on Earthquake Engineer, vol. 19, no. 2, pp. 11-15, 2003, in Chinese.

[2] J. S. Bo, X. L. Lig, and D. D. Liu, "Effect of soil layer construction on characteristic period of response spectrum," Earthquake Engineering and Engineering Vibration, vol. 23, no. 5, pp. 42-45, 2003, in Chinese.
[3] G. X. Chen and J. H. Chen, "The effect of depth and thickness of soft soil layer on earthquake response for deep soft site," World Information on Earthquake Engineering, vol. 20, no. 3, pp. 66-73, 2004, in Chinese.

[4] Z. H. ZHou, Y. P. Li, and Y. Zhou, "The effect of hard interlayer thickness on the site seismic response," Seismology and Geology, vol. 41, no. 5, pp. 1244-1265, 2019, in Chinese.

[5] F. Gao, X. C. Chen, and S. H. Yan, "Influence of permafrost and seasonally frozen soil on seismic responses of sites," Chinese Journal of Rock Mechanics and Engineering, vol. 25, no. 8, pp. 1639-1644, 2006, in Chinese.

[6] F. Gao, S. H. Yan, and X. C. Chen, "Analyses on seismic responses of ground," Chinese Journal of Rock Mechanics and Engineering, vol. 22, no. S2, pp. 2789-2793, 2003, in Chinese.

[7] W. K. Hu and Q. J. Chen, "Response characteristic analysis of soil site with deep deposit under different bedrock seismic wave," Structural Engineer, vol. 26, no. 5, pp. 85-90, 2010, in Chinese.

[8] D. D. Jin, G. X. Chen, and F. F. Dong, "Effects of soft interlayer on ground surface seismic response of Fuzhou Basi," Journal of Wuhan University of Technology, vol. 34, no. 12, pp. 83-88, 2012, in Chinese.

[9] H. Li, J. B. Zhang, and J. C. Wu, "Effects of soft and hard interlayers on ground motion characteristic," Journal of Earthquake Engineering, vol. 36, no. 3, pp. 441-445, 2014, in Chinese.

[10] G. X. Wang and K. P. Huang, "Effects of surface soil on ground motion characters," Earthquake Engineering and Engineering Vibration, vol. 33, no. 5, pp. 33-40, 2013, in Chinese.

[11] H. W. Wang, Z. J. Feng, and X. Q. Liu, "Quantitative analysis of ground motion peak acceleration field effect in shandong province," Seismology and Geology, vol. 37, no. 1, pp. 44-52, 2015, in Chinese.

[12] K. M. Yan, F. C. Liu, and C. H. Zhu, "Study on dynamic response characteristics of slope field with inclined soft interlayer under seismic action," Chinese Journal of Rock and Soil Mechanics and Engineering, vol. 36, no. 11, pp. 26862698, 2017, in Chinese.

[13] J. Su, Z. H. Zhou, Y. Zhou et al., "The characteristics of seismic response on hard interlayer sites," Advances in Civil Engineering, vol. 2020, Article ID 1425969, 11 pages, 2020.

[14] S. Jeong, D. Asimaki, J. Dafni, and J. Wartman, "How topography-dependent are topographic effects? complementary numerical modeling of centrifuge experiments," Soil Dynamics and Earthquake Engineering, vol. 116, pp. 654-667, 2019.

[15] M. K. Akin, S. L. Kramer, and T. Topal, "Dynamic soil characterization and site response estimation for Erbaa, Tokat (Turkey)," Natural Hazards, vol. 82, no. 3, pp. 1833-1868, 2016.

[16] A. Lessi-Cheimariou, I. J. Tromans, E. Rathje, and C. Robertson, "Sensitivity of surface hazard to different factors and site response analysis approaches: a case study for a soft rock site," Bulletin of Earthquake Engineering, vol. 17, no. 1, pp. 73-96, 2019.

[17] M. Badaoui, M. K. Berrah, and A. Mebarki, "Soil height randomness inflfluence on seismic response: case of an algiers site," Computers and Geotechnics, vol. 36, no. 1-2, pp. 102-112, 2009.

[18] N. Glinsky, E. Bertrand, and J. Régnier, "Numerical simulation of topographical and geological site effects. Applications to canonical topographies and Rognes hill, South East 
France," Soil Dynamics and Earthquake Engineering, vol. 116, pp. 620-636, 2019.

[19] I. M. Idriss and H. B. Seed, "Seismic response of horizontal soil layers," Journal of the Soil Mechanics and Foundations Division, vol. 94, no. 4, pp. 1003-1031, 1968.

[20] F. J. Sanchez-Sesma, "Site effects on strong ground motion," Soil Dynamics and Earthquake Engineering, vol. 6, no. 2, pp. 124-132, 1987.

[21] X. L. Chen, X. Jin, X. Tao, and L. Kang, "Analysis and evaluation of one-dimensional nonlinear dynamic constitutive relationship of soil mass," Earthquake Engineering and Engineering Vibration, vol. 6, pp. 147-157, 2006, in Chinese. 